\title{
Clinicopathological Presentation of Congenital Neck Mass in Children of Eastern Nepal
}

\author{
Shyam Thapa Chettri ${ }^{1}$, Smriti Karki ${ }^{2}$, Deepak Pauel ${ }^{1 *}$, Shankar Prasad Shah ${ }^{1}$, \\ Bajrang Prasad Sah ${ }^{1}$ and Sriti Manandhar ${ }^{1}$ \\ 'Department of ENT \& HNS, BPKIHS, Dharan Nepal \\ ${ }^{2}$ Department of Pathology, BPKIHS, Dharan Nepal
}

\begin{abstract}
Background: Paediatric neck mass are common problem which often require surgical intervention. More than $90 \%$ of them are benign in nature and most of them are congenital in origin accounting up to 55\%. They are asymptomatic in nature and may be associated with pain, infection and pressure symptoms.
\end{abstract}

Methods: It was a prospective study conducted in the tertiary care centre over a period of one year from 15 th June 2012 to 15 th June 2013. All cases were evaluated clinico-radiologically followed by cytology and then underwent surgery. Histopathology report was taken as a confirmatory diagnosis.

Result: Forty-five cases of congenital neck swelling were evaluated. Age of the patient range from 36 months to 15 years 4 months with male: female ratio of $1: 1$. About $58 \%$ of patient presented with lateral neck swelling and remaining were with midline neck swelling. Most common diagnosis was Thyroglossal duct cyst accounting for $48.8 \%$.

Conclusion: The most common congenital neck mass observed in eastern Nepal was thyroglossal duct cyst with most neck mass presenting as painless swelling.

\section{Keywords: Neck Mass, Congenital}

\section{Introduction}

Paediatric neck mass are common worldwide often requiring surgical consultation in paediatric centers. ${ }^{1,2}$ with $90 \%$ of the neck masses being benign and of these $55 \%$ congenital. ${ }^{3}$ Congenital neck masses presenting to the otolaryngologist could be thyroglossal duct cyst, lymphangioma, branchial cysts, dermoids, thymic cysts, haemangiomas, ectopic thyroid, and congenital cervical teratoma ${ }^{4}$ Congenital neck mass can present as painless, soft, fluctuant and mobile swelling which can be infected and be painful. Few can have pressure symptoms like difficulty in swallowing and difficulty in breathing. These masses present diagnostic and therapeutic challenges especially in many resource-poor centers where affected children often present late and there may be a lack of sophisticated imaging facilities required for prompt and precise diagnosis. ${ }^{5}$ We present our prospective evaluation of neck masses that had undergone diagnosis and treatment at our clinic in the last one year.

\section{Materials and Methods}

It was a prospective study in which 45 cases with congenital neck mass presenting in ENT OPD/ward between $15^{\text {th June }}$ 2012 to $15^{\text {th }}$ June 2013 were included to study the frequency and clinicopathological presentation of different congenital neck masses in eastern Nepal .Ethical approval from the institutional ethical review committee was taken.

Detail clinical history and thorough examination and ultrasonography with FNAC done to make out diagnosis. Histopathology followed in operated cases and diagnosis confirmed.

Data were recorded and analyzed. The inclusion criteria included all consented patients with congenital neck mass and neck swellings with infective origin were excluded.

\section{Result}

In our study the age of the patient ranges from 36 months to 15 years 4 months with male: female ratio of 1:1.14. All 45 cases presented with swelling in the neck, with 6 cases associated with pain and one with difficulty in breathing. Twenty-six (57.78\%) presented as lateral neck mass and 19 (42.2\%) presented as midline swelling. Among the lateral neck swelling 15 presented on left side and 11 presented on right aspect of neck. Most common congenital neck swelling was thyroglossal cyst found in 22 patients. Among the 22 thyroglossal duct cyst, 18(81.81\%) presented as midline mass and slightly off midline in 4 cases with 
$3(13.64 \%)$ presenting on left lateral side and $1(4.55 \%)$ on right side.

Out of 45 cases, the commonest neck swelling diagnosed was thyroglossal cyst in 22 cases, followed by 9 branchial cyst, 5 each for hemangioma, lymphangioma and 4 cases for dermoid cyst. Table 1

\section{Discussion}

Neck masses in pediatric age group are broadly of two types congenital and acquired. Congenital neck lesions reflect abnormal embryogenesis in head and neck development. They can be cystic, solid or vascular and are benign in nature. They can present as midline or lateral neck swelling. Thyroglosslal duct anomaly is the commonest congenital lesion and more than $90 \%$ time located in midline. Whereas branchial cyst, laryngocele, lymphangioma, hemangioma, and fibromatosis coli are common congenital neck swellings located in lateral neck. ${ }^{[6]}$

There is embryological difference between midline and lateral neck masses. Developmental malformations of branchial apparatus give rise to congenital neck masses mainly in lateral neck. There are four distinct branchial arches, and fifth arch is rudimentary which regresses latter one. Each arch coalesces with its contralateral counterpart ventrally on the midline and any faulty fusion of the arches in lateral region give rise to congenital lateral neck swelling.

${ }^{[7]}$ Thyroglossal duct cysts result from failure of complete obliteration of the thyroglossal duct during development of the thyroid gland. Up to two third of thyrogossal duct cyst are located in sub hyoid region and others are in lingual, suprahyoid and suprasternal region. ${ }^{[8]}$

The age of presentation range from 36 months to 15 years 4 months in the present study whereas it was 4 days to fifteen years in a 10 year study by Ratan K.N et al. ${ }^{9}$ The male to female ratio was $1: 1.14$ in the present study which was in agreement to the study by Mahmut Öet al [10]but was different from Rattan et al.study. 9 The commonest mode of presentation was painless neck swelling which was similar to the study by Taiseer H. A. et al. ${ }^{[11]}$

The commonest neck swelling observed in our study was thyroglossal cyst which accounted for $48.88 \%$ similar to the finding observed by different authours. ${ }^{[10-12]}$ The other neck swelling observed in our study were 9 branchial cyst, 5 each for hemangioma, lymphangioma and 4 cases for dermoid cyst which was consistent with the findings observed by Siddique et al. ${ }^{[13]}$

Surgery is the only mode of treatment of thyroglossal duct cysts and every attempt should be made to completely remove the cyst entire tract to the base of the tongue and body of hyoid bone otherwise there will be high chance of recurrence. If the body of hyoid bone and a cuff of the tongue base are included in the specimen as described by Sistrunk recurrence rate drops to $3 \% .^{[14]}$

Table1: Frequency of congenital neck masses

\begin{tabular}{|c|c|}
\hline Nature of mass & No.(\%) \\
\hline Thyroglossal cyst & 22(48.8\%) \\
\hline Branchial cyst & $9(20 \%)$ \\
\hline Haemangioma & $5(11.1 \%)$ \\
\hline Lymphangioma & $5(11.1 \%)$ \\
\hline Dermoid cyst & $4(8.9 \%)$ \\
\hline Total & $\mathbf{4 5}(\mathbf{1 0 0} \%)$ \\
\hline
\end{tabular}

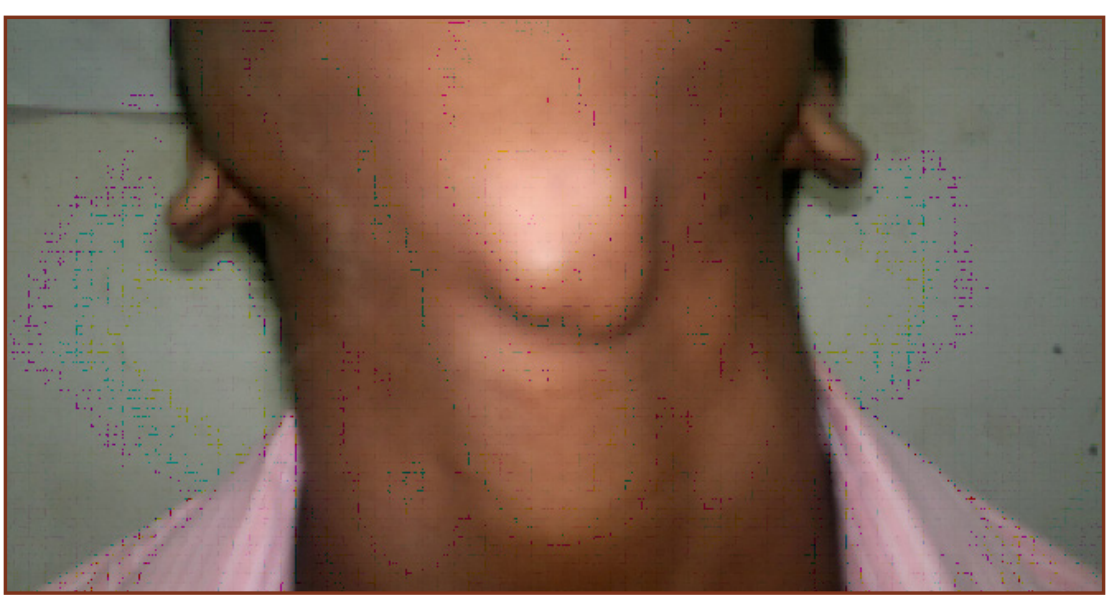

Fig. 1: Thyroglossal cyst. 


\section{Conclusion}

The most common congenital neck mass observed in eastern Nepal was thyroglossal duct cyst with most neck mass presenting as painless swelling.

\section{Reference}

1. Turkington JR, Paterson A, Sweeney LE, Thornbury GD. Neck masses in children. Br J Radio. 2005;78:75-85.

2. Tracy TF, Muratore. Management of common head and neck masses. Semin Pediatr Surg. 2007;16:3-13.

3. Maran A et al.Textbook of head and neck surgery and oncology. 5th ed.2012;214-226

4. Maran A et al.Textbook of head and neck surgery and oncology. 4th ed.2000;181-185

5. Malik A, Audit J, Rodriguez J, Hardjasudarma M. Pediatric neck masses: A pictural review for practicing radiologists. Curr Probe Diagn Radiol 2002;31:146-57.

6. Enepekides DJ. Management of congenital anomalies of the neck. Facial Plast Surg Clin North Am 2001;9(1):131-45

7. Gray SW: Skandalakis JE: The pharynx and its derivates, in Gray SW, Skandalakis JE (eds): Embryology for Surgeons (Philadelphia WB Saunders, 1972p. 15
8. Nicollas R, Guelfucci B, Roman S, et al: Congenital cysts and fistulas of the neck. Int $\mathrm{J}$ Pediatr Otorhinolaryngol 55:117, 2000

9. Rattan KN, Rattan S, Parihar D, Gulia JS, Yadav SP. Second branchial cleft fistula: is fistulogram necessary for complete excision. Int J Pediatr Otorhinolaryngol. 2006 Jun; 70(6); 1027-1030

10. Mahmut Ö, Mehtap K.Histopathological Examination of Patients Operated on for a Neck Mass: 4-Year Follow-Up Result.Turkish journal of pathology. 2011; 27, 134-137.

11. Taiseer H. A. et al . Congenital Neck Masses: A Descriptive Retrospective Study of 252 Cases. Journal of oral and maxillofacial surgery.2007; 65:2242-2247.

12. Ayugi JW, Ogeng'o JA, Macharia IM.Pattern of congenital neck masses in a Kenyan paediatric population. International Journal of Pediatric Otorhinolaryngology. 2010;74:64-66.

13. Siddique MA, Hossen M, Taous A, Clinical presentation of congenital neck mass in children. Bangladesh $\mathrm{J}$ Otorhinolaryngol. 2012. 18:16:22

14. Maddalozzo J, Venkatesan TK, Gupta P. Complications associated with the Sistrunk procedure. Laryngoscope 2001;111(1):119e23

*Corresponding author:

Dr. Deepak Paudel, Department of ENT \& HNS , BPKIHS Dharan Nepal

Phone: +91 9779852056991

Email: d_pakh@yahoo.com

Financial or other Competing Interests: None.

http://www.aamsjournal.com 